\title{
Launching of an American Medical College in the Middle East: Educational Challenges in a Multicultural Environment
}

\author{
David P. Hajjar ${ }^{1} \&$ Antonio M. Gotto, Jr. ${ }^{2}$ \\ ${ }^{1}$ Weill Cornell Graduate School of Medical Sciences, Cornell University, New York, NY, USA \\ ${ }^{2}$ Weill Cornell Medical College, Cornell University, New York, NY, USA \\ Correspondence: David P. Hajjar, PhD, Weill Cornell Medical College, 1300 York Avenue, New York, NY 10065, \\ USA. Tel: 1-212-746-6900. Email: dphajjar@med.cornell.edu
}

Received: April 3, 2013

Accepted: April 18, 2013

Online Published: April 22, 2013

doi:10.5430/ijhe.v2n2p67

URL: http://dx.doi.org/10.5430/ijhe.v2n2p67

\begin{abstract}
The graduation of the first class of medical students in May 2008 from the Weill Cornell Medical College in Qatar (WCMC-Q), Cornell University's branch campus in the Middle East, was the first time that an M.D. degree from an American university was awarded abroad. It marked a milestone in American higher education.

The establishment of WCMC-Q is part of a larger strategy to promote education and develop science policies in Qatar and other areas of the Gulf Arab States. Development of WCMC-Q has proceeded according to our institution's tripartite mission of fostering excellence in medical education, research, and clinical care. The focus of this article is the development of the educational program in Qatar since its inception, and it reviews critical success factors, the policies aimed at achieving our tripartite mission, and the challenges facing the promotion of medical education in the Gulf region. Critical factors in the success of this project include clearly defined educational objectives, a focus on academic quality and guaranteed academic freedom. Challenges include: 1) faculty recruitment and retention, 2) the integration of local high school students into a competitive science program, 3) the distance separating WCMC-Q from New York City where Weill Cornell Medical College-NY (WCMC) resides. As WCMC-Q continues to grow and expand its long-term mission, it may serve as a model for American universities seeking to establish branch campuses abroad for educational and medical training purposes.
\end{abstract}

Keywords: Educational policies, International medical curriculum, Medical school, Branch campus, Middle East, Qatar

\section{Early development}

On January 25, 2001, Cornell University and the Qatar Foundation for Education, Science and Community Development signed an agreement for the establishment of a branch medical campus in Qatar. The Qatar Foundation, an independent, private, non-profit, chartered organization set up in 1995 by an Emiri decree, is the main entity through which this energy-rich country seeks to develop a knowledge-based society, which is one of the most important development challenges faced by the Arab region (United Nations, 2003). Its strategy is to create a network of centers and organizations in collaboration with leading international institutions in order to become a regional leader in education, research, and technology development (Küster, 2010, Shetty, 2011). These initiatives aimed at educational reform are far-reaching and innovative, especially when compared to more modest efforts by other Gulf states to modernize educational systems (Yamani, 2006). The Qatar Foundation's flagship project, Education City, is a 2500-acre campus in Doha, the capital of this Arabian Gulf State, where six American universities are now operating branch campuses (Frank, 2006). WCMC-Q was the second campus to open in Education City, and the country's first co-educational institution of higher education; it remains the only medical school in Qatar, and one of thirty medical schools in the Gulf Cooperation Council countries (Bin Abdulrahman, 2008).

The Foundation's vision for establishing an academic medical center by bringing in a foreign partner matched the strategic plans of Cornell University and its Medical College in New York City (WCMC) for expanding their global academic ventures. Cornell University has had a long history of participating in a large number of international collaborations, including research and exchange programs in Europe, Asia, and Central and South America. Cornell sees these international ties as essential to fulfilling its academic mission in today's culturally and scientifically 
interconnected world, as well as critical to strengthening its competitive position in the global marketplace for education. Moreover, advancing global health has long been a key goal of the University and its Medical College. From a broader public service perspective, a branch medical college in the Middle East was seen as an important diplomatic initiative to build cultural bridges and help strengthen science and education in a region with an outstanding cultural heritage.

An increasing number of North American universities and academic health centers have been established abroad, although WCMC-Q remains the only medical school to offer an American M.D. (Bollag, 2006). These international activities can vary widely in scope, ranging from limited education and training programs to consulting or management services to fully or jointly owned clinical/education/research centers (Merritt, 2008). Establishment of an international branch campus differs from offshore medical schools, which are for-profit institutions of varying quality that train US and Canadian students who intend to return home to practice medicine (Eckhert, 2010). Verblik argues that international branch campuses typically fall into one of three models based on whether the new campus is wholly funded by the parent institution, externally funded by organizations in the host country, or supported through the use of local facilities (Verbik, 2006). He sees the Qatar Foundation's Education City as fitting into the third paradigm. Another analysis, which considers case studies in Asia and the Pacific, identifies transnational higher education as generally taking a government-regulated approach, a market-oriented approach, or a transitional approach from one to the other (Huang, 2006). WCMC-Q appears to fall outside this model, as it is a nonprofit organization that operates independent of the Qatari government.

In 2001, WCMC-Q began an extensive recruitment process for pre-medical and medical education faculty. Of WCMC-Q's tripartite mission to provide excellence in research, education, and clinical service, which it shares with its parent institution in New York, it was decided to concentrate initially on student education. As is the case in New York (and other medical colleges based in the U.S.), the faculty are primarily responsible for curriculum design, overall content, and implementation. In terms of governance, the Dean of the Faculty at WCMC-Q reports directly to Cornell University's Provost for Medical Affairs, who is also the Dean of the Weill Cornell Medical College in New York City; and, through this individual, to the President of Cornell University, WCMC Board of Overseers, and Cornell University Board of Trustees. The Cornell Boards of Overseers and Trustees are responsible for fiduciary oversight and its academic programs. The Qatar Foundation provides, and is responsible for, oversight of the facilities. The Foundation, which funds all operating costs associated with the program, determined that initially many of the students would probably come from outside Qatar, and that the program would thus function to support the broader region. Efforts now exist to enlist and train more Qatari students in medical education. A study of international branch campuses in the Arab Gulf States indicates that one of the major benefits of transnational higher education is training young people to have the skills necessary for employment in knowledge-based organizations (Wilkins, 2011).

\section{Admissions and Education}

WCMC-Q offers a fully integrated six-year program consisting of a two-year, non-degree, pre-medical component and a four-year medical curriculum leading to the M.D. degree. This degree is granted by Cornell University. All classes are co-educational and taught in English. The pre-medical and medical programs have separate admissions processes, and the requirements for the latter are the same as those at the New York campus. In fact, WCMC-NY reviews all applications for admission to WCMC-Q. Admissions requirements for the pre-med program include completion of a secondary school education, the SAT Reasoning Test, English language proficiency tests, and interviews. Admissions requirements for the medical program include the completion of pre-medical required course work, letters of evaluation, and the Medical College Admission Test (MCAT). For the 2012 -2013 academic year, the average science grade point average (GPA) for entering students was 3.5 in Qatar and 3.7 in New York. Academic standards and the medical curriculum remain similar across campuses.

The pre-medical program consists of courses in the basic sciences and mathematics, writing seminars, an introduction to medical ethics, and Cornell University's Psychology 101 class via e-Learning, as well as an introduction to the research laboratory. The purpose of this program is to help prepare students for medical school. For the 2012-2013 academic year, we accepted 15 men and 20 women into the entering pre-medical students class: the average SAT math score was 700; and the average TOEFL test was 110.

Similar to WCMC in New York, medical students in Doha are exposed to patient care from the earliest stage of their medical education. They receive instruction in the hospitals and clinics of the Hamad Medical Corporation (HMC), the state health care provider, which became affiliated with WCMC-Q in 2004. Students begin observing the doctor-patient relationship in the first year and take clinical clerkships in their third and fourth years. WCMC-Q 
physicians provide teaching and clinical care at HMC hospitals, where approximately $250 \mathrm{HMC}$ physicians have appointments as WCMC-Q clinical faculty. This partnership has been key to the fulfillment of WCMC-Q's educational mission. Currently, there are 273 (166 medical and 107 pre-medical) students from more than 30 different countries matriculating at WCMC-Q [Figure 1 and Table 1]. Thus, the medical school is truly international, with many students coming from the Middle East. For the first six years of the medical program, the admission rate from the pre-medical to the medical program was about $50 \%$ for all students.

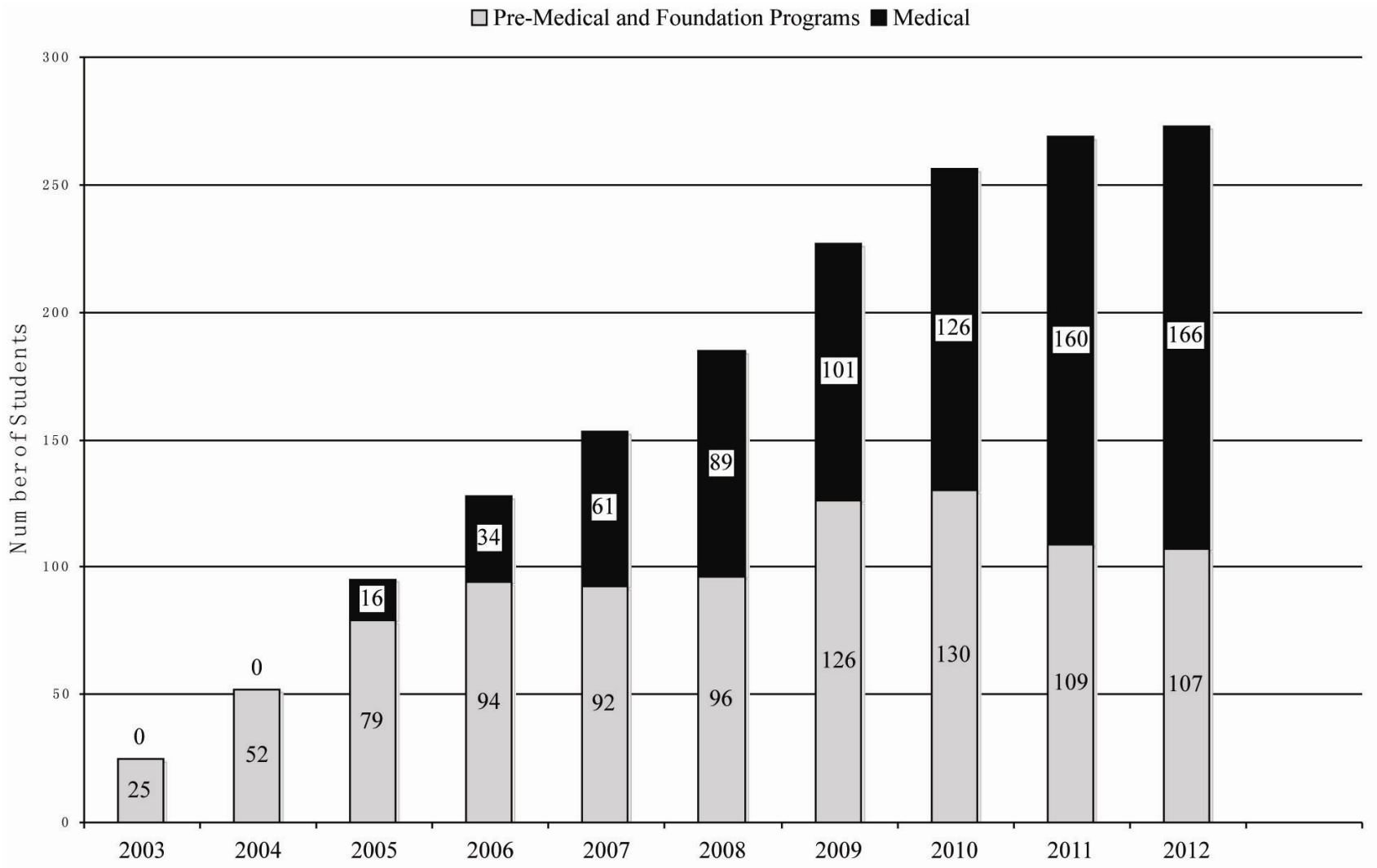

Figure 1. Total Number of Students in Pre-Medical/Foundation and Medical Programs, 2003-2012

Table 1. Representative Profile and Citizenship of Student Body: Last 3 Years

\begin{tabular}{lll}
\hline Distribution of Nationalities in the WCMC-Q Student Body* & \\
\hline Algeria & Iraq & Russia \\
Australia & Jordan & Saudi Arabia \\
Bahrain & Kenya & Sri Lanka \\
Bangladesh & Kuwait & Sudan \\
Bosnia & South Korea & Syria \\
Canada & Lebanon & Tanzania \\
Egypt & Mauritius & United Kingdom \\
France & Nepal & United Arab Emirates \\
Germany & Oman & USA \\
India & Pakistan & Yemen \\
Iran & Qatar & \\
\hline
\end{tabular}

*Pre-medical and medical students.

In terms of gender, the entering pre-medical classes have been equally balanced between men and women since 2002 . For six of the years, there were more women than men; for four years, the reverse was true. In 2011, the entering class of medical students contained 24 men and 19 women. Male and female students at WCMC-Q are treated similarly and receive the same educational benefits, and faculty and staff are careful to observe the customs and 
cultural aspects of Qatar, including those relating to gender. Students may choose to opt out of any social activity that they do not feel comfortable participating in.

Weill Cornell has always taken great pride in its medical curriculum and the educational policies designed to train highly competent medical students, and our challenge was to have a comparable educational experience for the students in Qatar. Ergo, we adapted the WCMC-NY curriculum in its entirety for on-site training in Qatar. The challenge of adapting the curriculum from an academic environment where all students have a four-year college degree and have completed significant pre-medical course work did exist since not all students who wanted to enter WCMC-Q had baccalaureate experience. Yet our educational policies, developed by our faculty and endorsed by the administration, embraced the concept that the curriculum "roadmap" of our New York City-based medical college would be followed in WCMC-Q (Table 2). WCMC-Q thus provided the opportunity to test the curriculum in a different cultural setting.

Table 2. Education Policies for WCMC-Q

Education Policies Developed for WCMC-Q

1. All educational curriculum requirements for graduation for WCMC-Q students are similar to those for WCMC-NY students. Therefore, "traditional" medical education at WCMC-NY will apply to the international domain.

2. Courses taught in WCMC-Q will be of the highest quality, delivered by reliable and consistent means, and the institution will provide academic, technical, clerical, and instructional design support services to students.

3. All WCMC-Q students must satisfy all requirements of the curriculum.

4. Student services and instructional materials, which are essential to the didactic phase of training, must be of the highest quality.

5. WCMC-Q will train faculty, staff, and students in the use of information technology and translational informatics ("bench to bedside" approach), as appropriate.

6. All faculty will be reviewed, compensated, and supervised according to Cornel1/WCMC guidelines.

7. The Academic Ethical Code of Behavior applies to the student body at WCMC-Q, including the time spent doing research study projects in New York.

8. Students will participate in first-rate clerkships offered by Hamad Medical Center. They will also participate in local community outreach programs, when appropriate.

9. In the true tradition of Cornell University, students in their fourth year of training will be encouraged to participate in a global outreach research project or a clinical project.

10. Students will participate in educational opportunities offered through seminars, Grand Round lecture events, journal club presentations, and clinical conferences, when appropriate.

As shown in Table 2, we subscribe to these education policies for two major reasons: 1) we did not want to create a two-tier system between graduating students from WCMC-NY and WCMC-Q, and 2) the creation and delivery of educational programs at international sites always raises questions about quality of teaching, control of the evaluation of curriculum content and reform, ownership of the educational content, faculty performance review and compensation. To date, there has been compliance and general faculty-student satisfaction with our educational policies now in practice for 10 years.

It is noteworthy that when WCMC-NY undergoes curriculum reform, WCMC-Q embraces these new changes in concepts and implementation, and the Dean at WCMC-Q is expected to effect these changes. Other Gulf medical colleges are also embracing curriculum reform and are moving towards hybrid problem-based learning curricula instead of traditional models (Bin Abdulrahman, 2008). To date, WCMC-Q students have adapted to our educational policies that were put in place by the faculty in order to obtain a medical education comparable to that in New York.

We also believe that our educational policies (Table 2) embrace the three basic principles articulated by Le Fanu (Le Fanu, 2006) for an inclusive education at our branch campus. We believe we have: democratization of teaching and learning (with faculty and students), socialization of teaching and learning (developing students' social identities with patients), and the systemization of teaching and learning (curriculum design, organization and implementation). 


\section{Research}

The successful launch of the education program in 2002 was the initial step in developing a fully functioning American-style medical school. In 2008, WCMC-Q launched its biomedical research program in an attempt to create a high-quality, competitive, and self-sustaining investigative research program (Chouchane, 2011). A major objective focused on the ability to initiate research projects that address significant health problems in Qatar (e.g., diabetes, cardiovascular disorders, complications of pregnancy, disorders of the newborn, cancers), utilizing molecular and genetic approaches. A research infrastructure, including administrative research support and shared-use core facilities, has already been developed. Cornell University and the Qatar Foundation signed an agreement to begin a comprehensive, five-year biomedical research program with recruitment of research faculty starting in 2008-2009. There are now 30 research principal investigators working in Doha at WCMC-Q. These efforts are being coordinated with initiatives led by the Qatar Foundation to build a national science funding infrastructure in Qatar.

Several years ago, the Qatar Foundation developed the Qatar National Research Fund to support research in Qatar in Education City and to support those researchers outside the country who wish to collaborate scientifically with WCMC-Q principal investigators; and, for WCMC-Q faculty to collaborate with WCMC-NY faculty. Through this competitive funding mechanism, we have been able to develop pragmatic approaches to faculty retention and the advancement of the faculty member's scholarly activities as researchers by providing independent, peer-reviewed grant support. These funds have assisted them in supporting their post-doctoral fellows, technicians and administrative personnel associated with doing basic research.

We strongly believe that student exposure to research is an important component of medical student education and that research capacity is crucial to the recruitment and retention of a highly qualified academic faculty.

To encourage students to start thinking about science, WCMC-Q created a summer research fellowship for pre-medical and medical students almost 10 years ago. These fellowships enable approximately 20 qualifying students to spend six to eight weeks during the summer in laboratories at either the main Cornell campus in Ithaca (pre-medical students) or at the Medical College campus in New York City (medical students). This program has been an important tool for exposing students to science at an early stage of their education, and it has been the policy of the Deans at WCMC and WCMC-Q to strongly encourage this interface with the faculty in New York.

\section{Clinical Care}

Currently, the government-funded Hamad General Hospital and Women's Hospital are the primary venues for WCMC-Q students to obtain medical school clinical training. These high-volume, multispecialty hospitals provide a breadth of clinical material, encompassing patients of all ages and races. In 2013 or 2014, with the opening of the Sidra Medical and Research Center, Qatar will have its first custom-designed academic medical center. Sidra will also enable the integration of WCMC-Q's tripartite mission of education, research, and clinical training in an ultra-modern facility. Among Gulf countries, the limited availability of clinical training facilities has been cited as a challenge for medical schools in the region (Hamdy, 2010). The opening of this venue will be an essential component of the Qatar Foundation's vision for WCMC-Q, and WCMC in New York has been instrumental in the ongoing planning of Sidra's services and facilities. Ultimately, the plan is for HMC and Sidra to become part of a broad-based academic healthcare system that will provide undergraduate and graduate clinical training opportunities for WCMC-Q students, residents, and fellows. The affiliation agreement for the Sidra Medical Center between the Qatar Foundation and Cornell University will promote state-of-the-art training for a new generation of physicians.

\section{Critical Factors for Success}

In October 2012, WCMC-Q celebrated the 10-year anniversary of its inauguration during which time it produced 112 new doctors from many nationalities. These graduated students have secured excellent residencies in the U.S. The residency matches occur through the traditional match mechanism. Medical students have "matched" at The NewYork-Presbyterian Hospital/Weill Cornell Medical Center, The Hamad Medical Center, Johns Hopkins University, Rush University Medical Center, The Methodist Hospital in Houston, the University of Minnesota, the Cleveland Clinic, and the University of Connecticut, among others.

Three factors have proven critical to the success of the program: clearly defined objectives, a commitment to standards and quality, and guaranteed academic freedom. 


\subsection{Clearly defined objectives}

It has been crucial to align the strategic imperatives of WCMC-Q with the vision of the Qatar Foundation. From the outset, the Qatar Foundation and WCMC-Q agreed that the objective of the new program was not only to provide excellence in education, research, and clinical care, but also to build research capacity in the context of contributing to the development of a knowledge-based society. This clear focus on quality and capacity building, which includes human capital, organizational, and infrastructure development, has proven critical in establishing a functional partnership, one based on matching expectations. Within the institution, this clear focus has also acted as a guiding principle that continues to frame strategic and operational decisions at every level, with all parts contributing to this long-term goal of building a sustainable academic program.

\subsection{Quality focus}

It is paramount that standards and quality for the Medical Colleges in Doha and New York are the same. This has been made feasible by the Qatar Foundation's generous support and unwavering commitment to the highest academic standards, as well as by WCMC-Q's close adherence to University and WCMC-NY educational policies and practices for faculty management and student admissions. For example, faculty candidates to be appointed in Doha, Qatar are interviewed in Doha and New York, and they are appointed by the academic departments of WCMC in New York (medical faculty) or at Cornell University in Ithaca (pre-medical faculty). They have to fulfill the criteria for faculty appointments in their respective academic departments. Currently, there are approximately 60-65 full-time WCMC-Q faculty members working and living in Doha [Figure 2]. Almost 2/3 of the faculty members are American, and 1/4 are either European or Canadian with many of them having preexisting family ties to the Gulf Arab region; the remaining are directly from the Middle East. This commitment to quality and standards anchors the program in Cornell University's academic tradition, offering the program the necessary legitimacy in the eyes of peer institutions, colleagues, prospective students, and residency programs. A similar focus on academic quality, sustained by university leadership, has been crucial to the success of the Arabian Gulf University College of Medicine and Medical Sciences, a unique venture managed by a multinational consortium of Gulf countries (Hamdy, 2006). This institution also found that cooperation with prestigious international universities and organizations was key to building an international reputation.

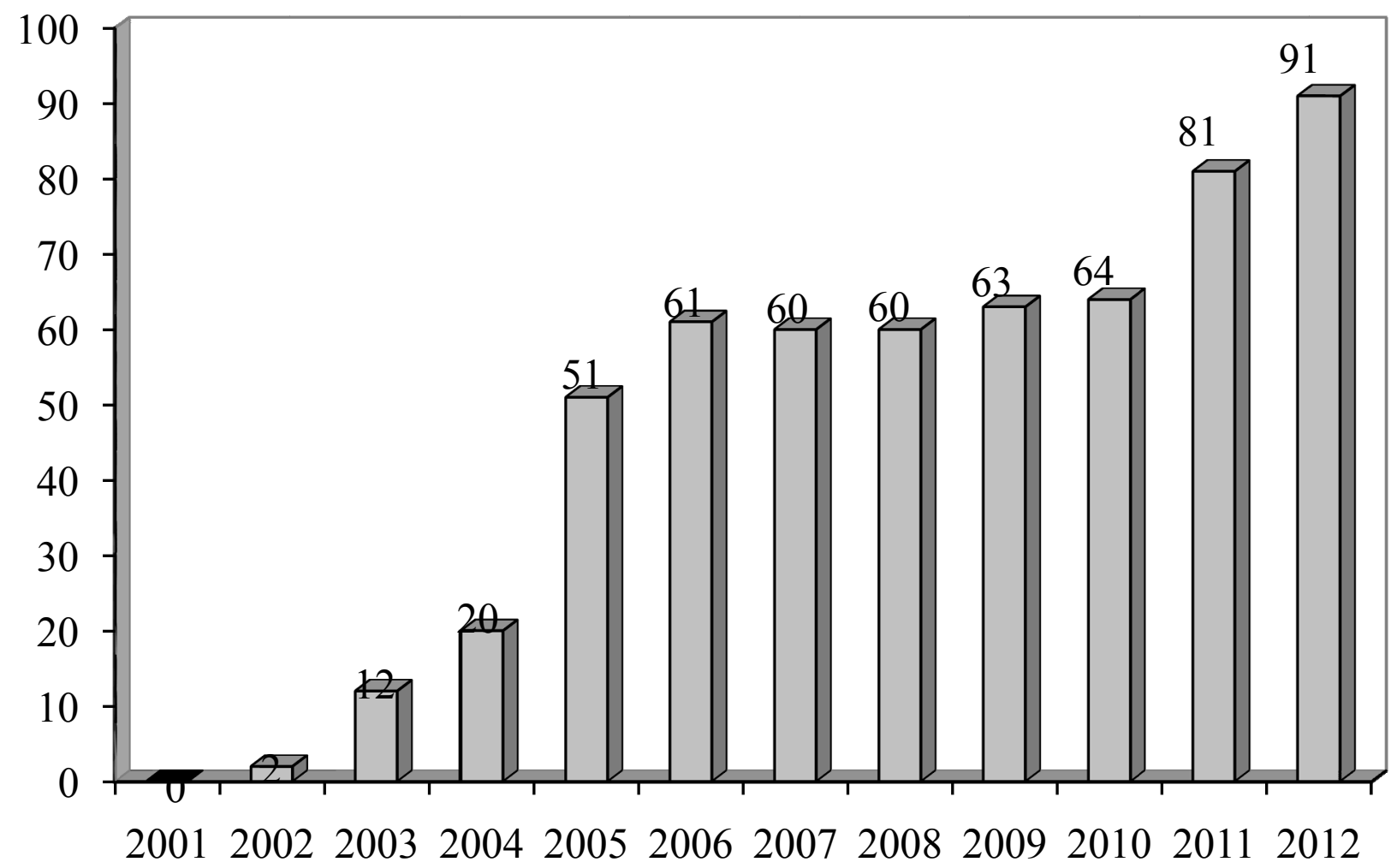

Figure 2. Academic Staff (Faculty/Non-Faculty Professionals), 2001-2012 


\subsection{Guaranteed academic freedom}

A pivotal guarantor of quality is the academic freedom and operational autonomy provided to WCMC-Q by the Qatar Foundation. The Foundation has given the Medical College in Doha absolute free reign in recruitment of staff and faculty, student selection, and the curriculum. Such a guarantee is seen as a necessity for Cornell University to be able to develop a legitimate academic program and to offer its medical degree.

\section{Challenges and Solutions}

As can be expected with an international, high-level education "start-up," multiple operational challenges present themselves.

The first challenge has been to attract and retain top academic talent, which is always demanding everywhere, but becomes an even larger challenge when recruiting to a nascent program in an environment that lacks many attributes normally found in an academically rich setting, including an established academic infrastructure and a critical mass of colleagues. A survey of Gulf medical schools confirms that faculty recruitment and retention is considered a major problem in the region (Hamdy, 2010). WCMC-Q has addressed this challenge, and they are recruiting exceptional people. In addition to the required professional qualifications, faculty and staff need a "can-do" mentality and a desire for adventure to successfully navigate the cultural, climate, and geographic differences that often exist between Qatar and their places of origin. During its first few years, WCMC-Q could have been accurately described as a start-up venture, which called for a problem-solving attitude to deal with daily emerging challenges. To adjust to the new environment, new junior faculty members have the opportunity to be paired with a mentor at WCMC-Q to help with the acclimatization process. As the institution has matured, and a critical mass of colleagues has been assembled at WCMC-Q, recruitment issues have become less pressing.

A second major challenge has been preparing local students entering the pre-medical program to meet admissions standards for the medical program. Building off a program established by the Qatar Foundation that provides one year of English instruction after high school, WCMC-Q established a unique Foundation Program that combines a year of English instruction with study skills to improve critical reasoning skills, plus introductory math and science courses. Early results have been encouraging. In addition, WCMC-Q has recruited several faculty members to teach English as a Second Language (ESL) and English comprehension and writing courses. WCMC-Q is implementing a long-term program to improve the English language skills of targeted high school students interested in a medical career. Other initiatives include a "teach-the-teacher" program, in which WCMC-Q faculty update Qatar high school teachers on new developments in science. We also established a Medicine Unlimited program, which provides seminars for high school students and their parents to increase their enthusiasm for the medical sciences. Both programs are successful, and they will be expanded in the coming year. Furthermore, the quality of high school graduates is expected to further improve as the country's comprehensive K-12 education reforms, which were implemented in 2002 and fall under the "Education for a New Era" program, bear fruit (Brewer, 2007). Still, exploring innovative approaches to help bridge the gap between high school and the medical program remains a priority.

The third challenge has been to overcome the approximately 7000 miles between the New York and Doha campuses - both in a geographic and cultural sense. In geographic terms, the goal is to maximize resource sharing, align operations of the two campuses as closely as possible, and facilitate exchange of ideas amongst faculty. Active use of information technology, especially video- and teleconferencing made broadly available to staff and faculty, has been able to overcome the eight-hour time difference and shifted work week schedule (in Qatar, the work week runs from Sunday to Thursday). For example, Yang describes the integration of library document delivery and interlibrary loan services between Texas A\&M and its branch campus in Qatar (Yang, 2009). At WCMC-Q, a number of courses regularly incorporate lectures from New York-based faculty, which are either recorded in advance or broadcast live via videoconferencing. In addition, New York faculty members regularly travel to Doha for weeklong visits. For the past 10 years, more than 50 faculty made this "commute" to help mount the teaching program, which also contributes to building ties between the two campuses. In cultural terms, the Qatar-based faculty and staff are offering cross-cultural awareness classes; in turn, students take a specially devised Medical Ethics and Humanities course, which takes into account non-Western approaches to medical ethics (Rodriguez del Pozo, 2005). The diversity of the faculty, staff, and student body has greatly enriched the academic experience.

\section{Future Directions: Has the Experiment Worked ?}

Over the past 10 years, Weill Cornell has laid a solid foundation for education, research, and clinical training in Qatar. Over the next few years, our goals will continue to focus on the following three areas: First, WCMC-Q seeks 
accreditation by the Liaison Committee on Medical Education (LCME), which currently considers only medical schools located in the United States and Canada. Accreditation of medical schools in the Gulf region, whether by the LCME or a regional organization, is key to maintaining high-quality educational standards and improving the health of the local population (World Health Organization, 2003). Second, it will continue to develop a comprehensive biomedical research program with basic, translational, and clinical components. And third, WCMC-Q will participate in the establishment of the first American-style academic medical center in the region with the aim of developing a cohesive clinical training program in the context of a healthcare delivery system.

Cornell University is committed to developing a world-class educational institution and to fostering the development of biomedical science in the Middle East. We are now close to reaching the critical mass of educators, scientists, and administrators necessary to ensure long-term success. Cornell University/WCMC is proud to play a role in Qatar's visionary plan to transform the country and region into a knowledge-based society. With regard to the success of our graduating classes in obtaining excellent residencies and fellowships since 2008, we can state that the "experiment" has worked so far, and that the educational policies we implemented, New York-style, are thriving in the Gulf Arab region in spite of the international academic hurdles.

Finally, we believe that collaboration in educational development is a strong force in advancing the medical profession in the Gulf Arab States. The country of Qatar has attempted to meet this challenge by "raising the bar" in this region of the world by developing a medical school with Cornell University, and with the addition of a world-class medical center called Sidra in its capital of Doha and its continued affiliation with the Hamad Medical Center, this will indeed make the difference. Clearly, education at the "professional" level for a sustainable society, one aimed at enhancing its knowledge base, is a key concept for the Qatari people, and they are willing to collaborate with worldwide partners to achieve this goal.

\section{Acknowledgement}

We wish to dedicate this manuscript to Sanford I. Weill, Chairman of the WCMC Board of Overseers, and a Cornell University alumnus, who had the foresight to believe that this global educational experiment could successfully work to train a whole new generation of exceptional physicians 7000 miles away.

\section{References}

Bin Abdulrahman, K. A. (2008). The current status of medical education in the Gulf Cooperation Council countries. Annals of Saudi Medicine, 28, 83-88. http://dx.doi.org/10.4103/0256-4947.51743.

Bollag, B. (2006). America's hot new export: Higher education. Chronicle of Higher Education, 52, A44-A47. [Online] Available: http://chronicle.com/article/America-s-Hot-New-Export-/24719.

Brewer, D. J., Augustine, C. H., Zellman, G. L., Ryan, G. W., Goldman, C.A., Stasz, C., Constant, L. (2007). Education for a new era: Design and implementation of K-12 education reform in Qatar. RAND-Qatar Policy Institute. Santa Monica, CA: RAND Corporation. [Online] Available: http://www.rand.org/pubs/monographs/MG548.html.

Chouchane, L., Mamtani, R., Al-Thani, M. H., Al-Thani, A. M., Ameduri, M., Sheikh, J. I. (2011). Medical education and research environment in Qatar: a new epoch for translational research in the Middle East. Journal of Translational Medicine, 9, 16. http://dx.doi.org/10.1186/1479-5876-9-16.

Eckhert, N. L. (2010). Private schools of the Caribbean: outsourcing medical education. Academic Medicine, 85(4), 622-30. http://dx.doi.org/10.1097/ACM.0b013e3181d2aee1.

Frank, L. (2006). Arab science: Qatar taps wells of knowledge. Science, 312, 46-47. http://dx.doi.org/10.1126/science.312.5770.46.

Hamdy, H. and Anderson, M. B. (2006). The Arabian Gulf University College of Medicine and Medical Sciences: A successful model of a multinational medical school. Academic Medicine, 81(12), 1085-90. http://dx.doi.org/10.1097/01.ACM.0000246680.82786.76.

Hamdy, H., Telmesani, A. W., Al Wardy, N., Abdel-Khalek, N., Carruthers, G., Hassan, F., ... Sheikh, J. (2010). Undergraduate medical education in the Gulf Cooperation Council: A multi-countries study (Parts 1 and 2). Medical Teacher 32, 219-224, 290-295. http://dx.doi.org/10.3109/01421590903389108 and http://dx.doi.org/10.3109/01421591003673730. 
Huang, F. (2006). Transnational Higher Education in Asia and the Pacific Region. Hiroshima, Japan: Research Institute for Higher Education, Hiroshima University. [Online] Available: http://rihe.hiroshima-u.ac.jp/tmp_djvu.php?id=68332.

Küster, A. (2010). Qatar - a new beginning? The development of a collaborative research and education environment in Education City, Doha. Serials, 23(1), 16-19. http://dx.doi.org/10.1629/2316.

Le Fanu, G. (2013). The inclusion of inclusive education in international development: lessons from New Guinea. International Journal of Educational Development, $33, \quad$ 139-148. http://dx.doi.org/10.1016/j.ijedudev.2012.03.006.

Merritt, M. G., Jr, Railey, C. J., Levin, S. A., Crone, R. K. (2008). Involvement abroad of U.S. academic health centers and major teaching hospitals: The developing landscape. Academic Medicine, 83, 541-549. http://dx.doi.org/10.1097/ACM.0b013e318172399e.

Rodríguez del Pozo, P., Fins, J. J. (2005). The globalization of education in medical ethics and humanities: Evolving pedagogy at Weill Cornell Medical College in Qatar. Academic Medicine, 80, 135-140. http://dx.doi.org/10.1097/00001888-200502000-00005

Shetty, P. (2011). Qatar sets its sights on global scientific domination. Lancet 378 (9801), 1453. http://dx.doi.org/10.1016/S0140-6736(11)61635-8.

United Nations Development Programme, Regional Bureau for Arab States (2003). Arab Human Development Report: Building a Knowledge Society. New York, NY: United Nations Publications. [Online] Available: http://hdr.undp.org/en/reports/regional/arabstates/name,3204,en.html.

Verbik, L. (2006). The international branch campus-models and trends [lecture]. [Online] Available: http://ihe.britishcouncil.org/sites/default/files/import-content/gg2-line-verbik-paper.pdf.

Wilkins, S. (2011). Who benefits from foreign universities in the Arab Gulf States? Australian Universities' Review, 53(1),73-83. [Online] Available: http://opus.bath.ac.uk/22814.

World Health Organization (2003). Regional consultation on the accreditation of health professions education in the Eastern Mediterranean Regions. Cairo: World Health Organization. [Online] Available: http://faculty.ksu.edu.sa/hisham/Documents/Medical\%20Education/English/Medical\%20Education/38.pdf.

Yamani, S (2006). Toward a national education development paradigm in the Arab world: a comparative study of Saudi Arabia and Qatar. Al Nakhlah Spring 2006, 1-8. [Online] Available: http://fletcher.tufts.edu/Al-Nakhlah/Archives/ /media/Fletcher/Microsites/al\%20Nakhlah/archives/2006/yamani .ashx.

Yang, Z. Y. (2009). Document delivery from Texas to Qatar: an international inter-campus service. Interlending \& Document Supply, 37(3), 116-125. http://dx.doi.org/10.1108/02641610910985576. 